\title{
NATURALEZA Y NATURALEZA HUMANA
}

\section{TEILHARD DE CHARDIN Y LA VIDA CÓSMICA: CIEN AÑOS DESPUÉS}

\author{
LEANDRO SEQUEIROS \\ Universidad de Sevilla \\ Vicepresidente de la Asociación de Amigos de Teilhard de Chardin
}

\begin{abstract}
RESUMEN. En el año 1916, Pierre Teilhard de Chardin lleva más de un año ejerciendo de camillero en el frente de batalla. Es entonces cuando se despliega el "genio teilhardiano". Su primer ensayo de tipo espiritual, filosófico y místico es "La Vida cósmica» de cuya redacción se cumple un siglo en 2016. Presentamos en este trabajo un comentario al contexto en el que se escribe este ensayo, así como la presentación de las ideas más sobresalientes del mismo con unas notas críticas aclaratorias. En otro lugar, presentamos el texto completo con una nueva traducción realizada a partir del texto francés de las Obras de Teilhard.
\end{abstract}

PALABRAS CLAVE: Teilhard de Chardin, espiritualidad, mística, cosmovisión, cósmico, Gran Guerra, Evolución, Materia.

\section{Teilhard de Chardin and the Cosmic Life: hundred years after}

ABSTRACT. Summary: On the year 1916, Teilhard de Chardin has already been for more than one year working as a stretcher carrier, at the war front. It is then that the «teilhardian genius» unfolds. His first essay of spiritual, philosophic and mystic type is "The Cosmic Life», the centenary of which falls in 2016. In this work we offer the context in which this essay was elaborated by the writer, and also we present the more outstanding ideas of the author, together with some clarifying and critical notes. In another place, we offer the complete text in a new translation, realized from the French text of Teilhard's Works.

KEY WORDS: Teilhard de Chardin, spirituality, mystic, cosmovision, cosmic, The Great War, Evolution, Matter.

\section{INTRODUCCIÓN}

En 1916, en el frente de batalla como camillero, Pierre Teilhard de Chardin (1881-1955) escribe a mano en un sencillo cuaderno que envía a su prima Margarita el que suele considerarse como el primer ensayo de cierta entidad en el que se expresa barroco, místico y desbordante el «genio teilhardiano». Ignoramos si existe algún inédito anterior a éste de contenidos similares. Parece que el «bautismo de lo real» —como él mismo escribe- hizo que en su interior se desencadenasen unas misteriosas energías capaces de revolucionar 
su mente. Y tuvo la capacidad inmensa de intentar plasmar en un brillante francés las vivencias más hondas de su alma de poeta místico y científico.

En la introducción al que se considera su segundo ensayo «El dominio del mundo y el reino de Dios $»^{1}$ (firmado unos meses después, el 26 de septiembre de 1916) reconoce que "Al escribir La Vida cósmica he pretendido llamar la atención sobre la posibilidad de una sana reconciliación entre Cristianismo y Mundo, sobre el terreno de la prosecución leal y convencida del Progreso, en comunión sincera con una fe en la Vida y en el valor de la Evolución. Mostré entonces al alma, una vez despertada a la pasión de las realidades extraindividuales y cósmicas, arrojándose sobre el Universo en el que se escuchaba por todas partes la llamada de una Divinidad; y he descrito cómo, bajo su impulso, el Absoluto se descubre y adquiere la figura de un movimiento de ascensión y de segregación, hecho de intrépida conquista, de socialización intensiva, de continuo desprendimiento, hasta el momento en que la Verdad descendida del Cielo, unida a la Verdad que se elabora sobre la Tierra, sintetiza todas las esperanzas del Mundo en la bendita Realidad de Cristo, cuyo Cuerpo es el centro de la Vida Elegida» (p. 97)

En este artículo situamos el ensayo «La Vida cósmica» dentro del contexto de la obra de Teilhard y en el marco de la experiencia personal de la guerra europea (1914-1919). Hemos realizado una nueva traducción de «La Vida cósmica» a partir del texto original francés ${ }^{2}$, cotejado con el texto en castellano ${ }^{3}$, accesible a los lectores interesados, al que se han añadido notas aclaratorias a pie de página y cuyo anticipo se ha publicado recientemente ${ }^{4}$.

\section{Pierre Teilhard de Chardin}

Marie-Joseph Pierre Teilhard de Chardin nace el 1 de mayo 1881 en la casa solariega de la familia en Sarcenat, cerca de Orcines (Puy-de-Dôme) ${ }^{5}$.

\footnotetext{
1 Pierre Teilhard de Chardin. Escritos del tiempo de guerra. Taurus, Madrid, 1968, pág. 93-118.

2 Pierre Teilhard de Chardin. «La Vie cosmique. Écrits du temps de la guerre. 1916-1919. Éditions du Seuil, París, 1965, pág. 17-82.

3 Pierre Teilhard de Chardin. «La Vida cósmica». Escritos del tiempo de guerra. Taurus, Madrid, 1968, pág. 19-91.

${ }_{4}$ Puede descargarse o adquirirse en papel en: http://www.bubok.es/libros/240254/LaVida-cosmica

5 Reseñamos algunos de los libros depositados en la Biblioteca Teilhard en la Asociación de Amigos de Teilhard (Córdoba, España): Álvarez DE JuAN, M., La formación del Científico y Teilhard de Chardin. Tesis Doctoral, Universidad de Valencia, 257 pp 1972; BARJon, L. Y Leroy, P., La carrière scientifique de Pierre Teilhard de Chardin. Éditions du Rocher, Monaco, 1964, 141 páginas; Barthéleny-Madaule, M., Bergson et Teilhard de Chardin. Éditions du Seuil, Paris, 1963, 686 pág.; Charmonneau, B., Teilhard de Chardin, prophète d'une âge totalitaire. Essai. Èditions Denoël, Paris, 1963, 222 pág.; Chauchard, P., L'être humanin, selon Teilhard de Chardin. Ses aspects complémentaires dans la phénoménologie scientifique et la pensée chrétienne. Lecoffre, Paris, 1959, 237 pág.; Chauchard, P., La pensée scientifique de Teilhard.
} 
Era el cuarto de los hijos de Emmanuel Teilhard de Chardin y Berthe-Adèle de Dompierre d'Hornoy. Una familia muy religiosa y bien establecida. Una selección de datos nos ayuda a centrar su figura ${ }^{6}$.

En el año 1899, ingresa (con 18 años) en el noviciado de la Compañía de Jesús en Aix-en-Provence. Posteriormente realiza estudios de filosofía en Jersey y entre 1905-1908 ejerce como profesor de química en el Colegio de la Sagrada Familia en El Cairo. Más tarde, entre 1908 y 1932 realiza sus estudios de Teología en Ore Place (Hasting, Sussex). En 1911 es ordenado sacerdote y sus superiores lo destinan a estudiar ciencias en París.

\section{Su formación intelectual}

Podemos considerar que, entre 1912 y 1923 se desarrolla la etapa inicial de la formación científica de Teilhard y de la publicación de los primeros trabajos geológicos y paleontológicos en Europa. En 1912 tiene lugar la primera entrevista con Marcellin Boule, profesor de paleontología en el Museo de Historia Natural de París. Bajo su dirección, asiste a cursos de Geología y Paleontología.

Al estallar la Primera Guerra Mundial Teilhard, a pesar de su condición de sacerdote, fue movilizado. Desde 1915 actúa como camillero en el 21

Édit. Universitaires, 1965, 270 pp.; Convez, M., De la ciencia a la fe. Teilhard de Chardin. Mensajero, 1967; Crespy, G. La pensée théologique de Teilhard de Chardin. Édit. Universitaires, París, 1961,231 pp.; Crespy, G., Ensayo sobre Teilhard d Chardin. De la ciencia a la teología. Hinneni, Salamanca, 1967, 227 pág.; СuÉnot, C., Pierre Teilhard de Chardin. Le grandes étapes de son évolution. Plon, Paris, 1958, 489 + XLIX pág.; CuÉnot, C. (editor). Teilhard de Chardin et la pensée catholique. Colloque de Venice. Éditions du Seuil, Paris, 1965, 267 pág.; De Lubac, H., La pensée religieuse du Pére Teilhard de Chardin. Aubier, Paris, 1962, 374 pág.; D’Ouince, R., Un prophète en procès: Teilhard de Chardin dans l'Église de son temps. Aubier, Paris, 1970 colección Intelligence de la foi, 259 pág.; D’Ouince, R., Un prophète en procès: Teilhard de Chardin et l'avenir de la pensée chrétienne. Aubier, Paris, 1970, colección Intelligence de la foi, 267 pág.; Galleni, L., Darwin, Teilhard de Chardin y los otros. Las tres teorías de la evolución. Editorial Epifanía, Buenos Aires, 2010, 149 pág.; Herrán Gascón, A dE LA Teilhard de Chardin. Vuelve el hombre. Editorial Ciencia, Madrid, 1993, 133 pág.; Leon-Dufour, M., Teilhard de Chadin y el problema del porvenir del hombre. Cuadernos Taurus, 86, 1969, 109 pp; Mooney, $\mathrm{C}_{\mathrm{H}}$. F., Teilhard de Chardin and the Mysery of Christ. Collins, Londres, 1966; MuÑoz, F., De la Fenomenología a la Cristología. Una aproximación al pensamiento de Pierre Teilhard de Chardin. Autoedición, 2013, 271 pág.; Pérez De LaBorda, A., La filosofía de Pierre Teilhard de Chardin. Ediciones Encuentro, Madrid, 2001, 474 pp.; Riaza, F. Introducción al pensamiento de Teilhard de Chardin. Cuadernos del Personalismo, 1992, 62 pág.; Rideau, E., La pensée du Pére Teilhard de Chardin. Éditions du Seuil, Paris, 1963, 590 pág.; Seoueiros, L. Teihard en el corazón. Bubok, 2010, 230 pp; SequeIros, L., En todo amar y servir. La diafanía de lo divino en el corazón del Universo. Bubok, 2012, 163 pp.; Segueiros, L. y Castellano Barón, F. J., Amigos de Teilhard en España. Aproximación histórica. Bubok ediciones, Córdoba, 10 de abril de 2015, 165 páginas; Tresmontant, C. Introduction a la pensée d Teilhard de Chardin. Seuil, Paris, 1956, 131 pp.; Tresmontant, C., Introducción al pensamiento de Teilhard de Chardin. Cuadernos Taurus, Madrid, 1960, 96 pág.

6 Tal vez la biografía más documentada es la de Cuènot, C., Pierre Teilhard de Chardin. Le grandes étapes de son évolution. Plon, Paris, 1958, 489 + XLIX pág. 
regimiento mixto de zuavos y tiradores, situado en la primera línea de fuego. Está en el frente de batalla hasta 1919 en que es desmovilizado. Regresa a la Universidad y obtiene en la Sorbona la licenciatura en Ciencias Naturales. Desde 1920 se dedica intensamente a las tareas de la Tesis Doctoral. Esta Tesis es defendida en 1922 con el título Los Mamíferos del Eoceno inferior francés y sus yacimientos. Inicia la docencia universitaria y es nombrado Encargado de curso de paleontología y geología en el Instituto Católico de París.

Pero esta tarea va a durar poco tiempo para el joven Teilhard: los superiores lo destinan a China. Se inicia la estancia en Tientsin, entre 1923 y 1931. Entre 1928-1929 Teilhard es nombrado consejero del Servicio Geológico de China. Pronto lo veremos como Colaborador en las excavaciones paleontológicas humanas de Choukoutien, cerca de Pekín como asesor de geología. En el año 1930, participa en la Expedición centroasiática (Mongolia) del American Museum of Natural History. Un año después, en 1931, Teilhard colabora en el estudio del Sinanthropus pekinensis, en hombre fósil de China, emparentado con el Pithecántropo (Homo erectus) de Java. Estos acontecimientos le empujaron al corazón de la comunidad científica de su tiempo, tanto en el campo de la prehistoria como de la paleontología y de la geología. Por otra parte, estos años son también tiempos de una gran actividad literaria que, desgraciadamente, no le fue permitido publicar, aunque se difundía multicopiada.

Entre 1931 y 1939 tiene lugar la estancia de Teilhard de Chardin en la ciudad de Pekín, donde mantiene una densa actividad científica, espiritual y filosófica. Entre los años 1931 y 1932 participa en el que fue llamado «El Crucero Amarillo», una expedición científica al corazón de China, impulsada por la fundación Citroën en Asia. Más tarde, entre 1932 y 1936, colabora en diversas campañas geológicas y paleontológicas a lo largo y ancho de China. Desde 1939 a 1946, Teilhard queda inmovilizado en China debido a las operaciones bélicas de la Guerra Mundial. Pero esta situación no bloquea su creatividad: en 1940 (con 59 años) crea con el padre Pierre Leroy el Instituto de Geobiología de Pekin. Pero en 1946 los jesuitas son deportados de China. Los últimos diez años de la vida de Teilhard discurren entre Estados Unidos y Francia, con viajes científicos esporádicos a otros países. En el año 1955, Teilhard muere repentinamente de infarto en Nueva York el día 10 de abril (día de Resurrección).

\section{Pierre Teilhard de Chardin y la Gran Guerra}

Hemos considerado de interés para los lectores situar a Teilhard en el marco global de su vida para entender cómo, «La Vida cósmica», su primer ensayo de síntesis, fue el punto de partida de toda su gran aventura intelectual. « L a Vida cósmica» nace de una doble experiencia interior: por un lado, la vivencia terrible de la muerte, la violencia irracional y la degradación humana trabajando como camillero en el frente de batalla; por otra parte, los densos y largos períodos de honda presencia de Dios que lo muestran como místico. Teilhard, en el frente de batalla, fue testigo de excepción del primer gran conflicto armado del siglo XX, la Primera Guerra Mundial. Esta movilizó a más de 70 millones de soldados 
de los cinco continentes y dejó cerca de diez millones de muertos y 20 millones de soldados heridos. La guerra también dejó millones de muertos civiles y provocó la caída de los imperios ruso, austro-húngaro, alemán y otomano.

La Primera Guerra Mundial, también conocida como «Guerra Europea» o la «Gran Guerra», fue un conflicto armado desarrollado principalmente en Europa, que dio comienzo el 28 de julio de 1914 y finalizó el 11 de noviembre de 1918, cuando Alemania pidió el armisticio y más tarde el 28 de junio de 1919, los países en guerra firmaron el Tratado de Versalles.

Algunas fechas más importantes nos ayudan a situar a Teilhard en el tablero sangriento de la Guerra Europea. El 28 de junio de 1914, el estudiante nacionalista serbio Gavrilo Princip asesina en Sarajevo (Bosnia Herzegovina) al archiduque Francisco Fernando de Habsburgo, heredero del trono del Imperio Austrohúngaro. Un mes más tarde, el 28 de julio, Austria-Hungría declara la guerra a Serbia (mediante un telegrama) y el 30 de julio, se produce una Movilización general en Rusia, aliada de Serbia.

El 1 de agosto, Alemania declara la guerra a Rusia. Es entonces cuando Francia y Alemania decretan la movilización general. El día 3 de agosto, Alemania declara la guerra a Francia y el 4 de agosto, las tropas alemanas cruzan Bélgica (país neutral) y entran en Francia. El Reino Unido declara la guerra a Alemania. Se inicia a partir del 19 de agosto la llamada «Batalla de fronteras» en el norte (frontera franco-belga) y el este (frontera francoalemana). Las tropas francesas retroceden 200 kilómetros.

Entre los días 6 y 9 de septiembre de 1914 tiene lugar la primera batalla del Marne (este de París). Una contraofensiva franco-británica frena el avance de los alemanes, a menos de 40 kilómetros de París, y los hace retroceder hacia el norte. Cerca de un millón de soldados franceses y británicos se enfrentan con 800.000 alemanes.

El 21 de febrero de 1916, marca el comienzo de la batalla de Verdún (que se prolonga hasta el 18 de diciembre), con el resultado de 500.000 muertos, franceses y alemanes. Ya en 1917, entre el 16 de abril y el 9 de mayo, se produce el fracaso de la ofensiva francesa en el Camino de las Damas, en el frente de Champaña (noreste de París), que deja decenas de miles de muertos. El 15 de diciembre tiene lugar en Armisticio de Brest-Litovsk entre Rusia y los imperios centrales. Por fin, el 3 de marzo de 1918 se firma un tratado de paz. La Gran Guerra ha terminado, llevándose consigo millones de muertos y el arrasamiento de países enteros.

\section{Teilhard en la primera guerra mundial}

Nos ha parecido presentar estos datos para situar a Pierre Teilhard de Chardin. Entre 1914 y 1919, Pierre Teilhard de Chardin permanece movilizado en el frente como camillero recibiendo la Medalla al Mérito Militar y Legión de honor. Precisamente, entre estos años, 1916 y 1919, Teilhard redacta sus 18 primeros ensayos de síntesis luminosa entre los que destacan «La Vida cósmica» (1916), «El Medio místico» (1917), «La Unión creadora» (1917), «Mi Universo» 
(1918), «El Sacerdote» (1918) y «La potencia espiritual de la materia» (1919) ${ }^{7}$. En ellos ya se transluce lo que será el núcleo de su pensamiento.

Estos son algunos de los datos más relevantes de la hoja de servicio de Pierre Teilhard de Chardin, tal como minuciosamente lo describe uno de sus primeros biógrafos, el profesor Claude Cuénot $^{8}$. Muchos datos de gran interés sobre sus actividades en el frente y sus reflexiones espirituales están reflejados en sus cartas, agrupadas en el volumen XVI de sus obras, bajo el título Génesis de un pensamiento9. En el mes de agosto de 1914, Teilhard no está aún movilizado. Una junta de clasificación le había declarado inútil parcial para el servicio militar en 1902 y en 1903; una nueva revisión, lo declaró apto para servicios auxiliares en 1904. Eran sus años de estudiante jesuita y debía ser la estrategia para que no tuvieran que hacer el servicio militar. Teilhard, pues, puede continuar con su formación religiosa y los estudios científicos. Incluso, tras la batalla del Marne, a la que hemos aludido más arriba, puede eludir ser movilizado y incluso comienza en Cantorbery la etapa que la Compañía de Jesús denomina la «Tercera Probación» ${ }^{10}$.

Teilhard no terminará este año de Tercera Probación. Las urgencias de la guerra hacen que un nuevo reconocimiento médico y militar (en diciembre de 1914) le declare «útil para todo servicio». Movilizado casi inmediatamente e incorporado a la $13^{\mathrm{a}}$ sección de Sanidad, Teilhard pasa un tiempo en Vichy y después en Clermont-Ferrand.

Pero esto no va con su carácter. No le gusta el trabajo de oficina. A sus 33 años Teilhard desea ir al frente de batalla. Verá satisfecho su deseo. El 20 de

$7 \quad$ Todos ellos se publicaron en el volumen XII de las Oeuvres de Teilhard de Chardin. Y la versión castellana en: Pierre TeIlHard DE Chardin. Escritos del tiempo de guerra. Taurus, Madrid, 1968, 470 páginas. La precipitación en la traducción de estos ensayos dio lugar a errores de traducción y a erratas de imprenta que hemos intentado corregir realizando nuevas traducciones a partir de la edición francesa.

8 CuÈnot, C., Pierre Teilhard de Chardin. Le grandes étapes de son évolution. Plon, Paris, 1958, 489 + XLIX pág; edición española: Сuénot, C., Pierre Teilhard de Chardin. Las grandes etapas de su evolución. Taurus, Madrid, 1967, 640 páginas (sobre todo, a partir de la página 53).

9 Pierre Teilhard de Chardin. Genèse d'une pensée. Bernard Grasset editeur, París, 1961. Edición castellana: Génesis de un pensamiento. Cartas (1914-1919). Taurus, Madrid, 1963. Contiene las cartas de Teilhard a su prima Margarita. Al fallecer esta en accidente de automóvil, la edición de las cartas fue completada por Alice Teillard-Chambon y Max Henri Bégouën, que redactan la presentación. Las cartas están precedidas de una introducción de Claude Aragonnès. Traducción de Teófilo Delgado. 369 páginas. En la introducción de Claude Aragonnès (su prima Margarita Teillard-Chambon) leemos (pág. 31): «De entre los acontecimientos exteriores de su vida, la guerra ha sido para el Padre Teilhard probablemente el más decisivo. Ha tenido sobre su vida una repercusión profunda. No es exagerado decir (así lo pensaba y así lo decía él) que la guerra le ha revelado a sí mismo. De todos modos, la guerra vino a precipitar un desarrollo interior que no se hubiera producido tan pronto ni, seguramente, tan irresistiblemente, sin las circunstancias que han acrecido considerablemente su experiencia humana, puesto su espíritu en movimiento y templado su carácter».

10 La «Tercera Probación» es una etapa de un año, finalizados los estudios teológicos, durante la cual los jóvenes jesuitas hacer una síntesis personal de toda su larga formación y se preparan para la Misión que la Compañía de Jesús quiera encomendarles en el futuro. 
enero de 1915, ya es camillero de segunda clase en el $8^{\circ}$ regimiento de choque de tiradores marroquíes. Este regimiento se convierte desde el 22 de junio de 1915 , en el $4^{\circ}$ regimiento de zuavos y tiradores.

Los primeros meses de 1915 los pasa Teilhard en los confines de Oise y del Somme, aproximadamente en el ángulo que formaba la línea del frente que, procedente del este, se remontaba hacia el norte de Francia. En abril y mayo y en agosto de 1915, el $4^{\circ}$ mixto está en el sector de Ypes. Luego, en septiembre del mismo año participa en la gran ofensiva de Champaña, especialmente brutal y mortífera, a la que hemos aludido. En junio, en agosto, en octubre, y en diciembre de 1916 nuevos actos heroicos en el frente, le cubre de gloria en Verdún.

En 1917 volvemos a encontrarlo en Champaña, en la región del Chemin-desDames, cerca del Ainse, y después, en las pendientes septentrionales al oeste de Soissons, participa de lleno en la segunda batalla del Marne y más tarde, participa en la contraofensiva.

En octubre de 1918 goza de una especie de vacaciones muy cerca de la Alta Alsacia y de la frontera suiza. A la noticia del armisticio, el regimiento se mueve hacia Alsacia y una delegación del $4^{\circ}$ mixto de zuavos y tiradores asiste, el 25 de noviembre de 1918, a la memorable entrada en Estrasburgo. El 30 de enero de 1919, el regimiento penetra en Alemania, en Baden, por el puente de Kehl. Para Teilhard, la guerra ha terminado.

Una guerra parece que, en principio, es incompatible con la vida intelectual. Pero durante los períodos de reposo, Teilhard —según sus biógrafos y sus cartasllenó, con su letra a la vez menuda, rápida, enérgica y distinguida, cuadernos enteros en los que confiere a su pensamiento una formulación ya compleja y rica.

Es curioso que Teilhard mantuvo en estos años una densa correspondencia con los hermanos Bégouën, apasionados por la arqueología. Y llega a esbozar una hipótesis sobre la historia geológica del lugar cercano al campo de batalla. Observa, examina, anota datos y reconstruye la historia de la Tierra a partir de los cortes geológicos y los depósitos de la Era Terciaria que aparecen en las trincheras de los alrededores de Reims. De igual modo, va recogiendo muestras de fósiles, sin sospechar que, enfrente, los alemanes recogen también, en sus obras subterráneas, muestras geológicas que enviaban a Munich, donde las estudiara el geólogo Max Schlosser.

Como escribe Cuènot (opus cit., pág. 68) Teilhard hizo suyo lo que decía Baudelaire, «me has dado tu cieno y yo lo he convertido en oro». Hizo oro del cieno de las trincheras, porque poseía el don sobrenatural de extraer de las cosas y de los seres la savia mediante la cual crecía para Dios.

Pero eso no es todo. Su biógrafo Claude Cuènot (opus cit, pág. 68) cree que fue la lectura de L'évolution créatrice de Henri Bergson ${ }^{11}$ influyó de modo radical sobre la cosmovisión de Teilhard. «La lectura de La Evolución creadora

11 Bergson, H., La Evolución creadora. Colección Austral, Madrid, 1985. Henri-Louis Bergson (1859-1941) publicó L'évolution créatrice en 1907. Posiblemente, Teilhard lo leyó con avidez durante sus años de estudio de Teología en Inglaterra. Ver: BaRTÉLEMY-MADAule, J., «Bergson et Teilhard de Chardin». Les études bergsoniennes, París, 1960, volumen V, pág. 65-71. 
de Bergson fue más bien la ocasión de una toma de conciencia personal, encuentro de una evidencia interior y de la simple necesidad de comprender los datos de la ciencia, que solo el evolucionismo hace inteligibles (...) A partir de entonces, la unidad del mundo es a sus ojos de naturaleza dinámica o evolutiva, el universo no es ya un cosmos inmóvil, sino una cosmogénesis, y todo se desarrolla en un "espacio-tiempo» biológico. No sabríamos establecer un paralelo entre los conceptos bergsonianos y teilhardianos de evolución» ${ }^{12}$.

Como reconoce el mismo Teilhard en «El Corazón de la Materia» ${ }^{13}$, en sus años de Teología en Hasting (1909-1912) la lectura de Bergson le impulsó a «la conciencia de una Deriva profunda, ontológica, total, del Universo». En Teilhard se produce el «despertar cósmico» y, como escribe el «La Vida cósmica», experimenta «el valor beatificante de la Santa Evolución». Todo en él «expresa felizmente el sentimiento de la omnipresencia de Dios, el abandono total del místico a la voluntad divina, y ese esfuerzo por comulgar con lo Invisible por intermedio del mundo visible, reconciliando así el Reino de Dios con el amor cósmico» ${ }^{14}$.

\section{Presentación de «la Vida Cósmica» (1916) de Pierre Teilhard de Chardin}

Escribe su biógrafo Claude Cuènot: «En un principio, la vida en las trincheras parece obrar como un catalizador sobre el espíritu del joven jesuita, y la primera síntesis es La Vida cósmica (24 de marzo de 1916), compuesta sin duda en los alrededores de Nieuport. El Padre Teilhard quiere dejar que se desborde su amor a la materia y a la vida y armonizarlo con la adoración a la única, absoluta y definitiva Divinidad. Parte del hecho inicial, fundamental, de que cada uno de nosotros está ligado, a través de todas sus fibras materiales, orgánicas, psíquicas, a todo lo que le rodea. La mónada humana, como toda mónada, es esencialmente cósmica» (opus cit., pág. 69)

Esta intuición intelectual, poética, espiritual y mística inicial le acompañará toda la vida. De forma que años más tarde, lo expresa. Muy explícita es su confesión en Como yo creo (escrita en octubre de 1934) ${ }^{15}$ : "La originalidad de mi creencia consiste en esto: que arraiga en dos dimensiones de la vida, consideradas habitualmente como antagónicas. Por mi educación y formación intelectual, pertenezco a los «hijos del cielo», pero por mi carácter y mis estudios profesionales soy un «hijo de la Tierra». (...) Al término de mi experiencia, después de treinta años consagrados a la búsqueda de la unidad interior, tengo la impresión de que se ha realizado de modo natural, una síntesis entre

12 CuÈnOT, C., opus cit., pag. 68-69.

13 Pierre Teilhard de Chardin. «El Corazón de la Materia» (1950). El Corazón de la Materia, Sal Terrae, 2002, pág. 26-30.

14 CuÈnot, C., opus cit., pag. 70.

15 Pierre Teilhard de Chardin. Como yo creo. Taurus, Madrid, 1970 pág. 105-106. 
las dos corrientes que tiran de mí: la una no ha ahogado a la otra. Hoy creo, probablemente, más que nunca en Dios, y al propio tiempo, más que nunca, en el mundo».

Este doble impulso hacia Dios y hacia los humanos, hacia lo material y hacia lo espiritual, hacia lo trascendente y lo inmanente, hacia lo físico y lo metafísico le acompañará siempre. Y su síntesis es un intento de armonización entre ambas tendencias. De alguna manera, todo lo material, lo humano, lo inmanente, lo terreno está apuntando, creciendo, evolucionando hacia lo espiritual, lo ultrahumano, lo sobrenatural, lo metafísico, lo teológico, lo divino...Esa fue una de sus primeras intuiciones.

\section{El texto editado de "La Vida cósmica»}

El texto original francés y su traducción española editada que ha llegado hasta nosotros de "La Vida cósmica» se inicia con una dedicatoria muy significativa: "LA VIDA CÓSMICA. A la Terra Mater y por medio de ella sobre todo a Cristo Jesús». Este título es ya un resumen apretado de su intento en este ensayo. Es la declaración de intenciones de Teilhard, su deseo más profundo al redactar este texto: que el gusto por las cosas de la tierra le lleven a sentir la densidad del Dios profundo que se muestra en las cosas.

Se ha discutido mucho sobre el posible panteísmo de Teilhard. Pero — como más adelante comentamos - su postura se distancia claramente del «todas las cosas son Dios» de los filósofos panteístas para percibir - como escribe San Ignacio en el Libro de los Ejercicios Espirituales-que Dios está y se manifiesta en todas las cosas. Las cosas no son Dios; Dios está en las cosas.

Tras el título que el mismo Teilhard dio a su ensayo, los editores incluyen una breve presentación del mismo ${ }^{16}$ : "La Vida cósmica», cuya redacción fue terminada el 24 de marzo de 1916, en Nieuport, es el primero de los escritos netamente teilhardianos que poseemos». Y añade: «Presentado por el padre Teilhard de Chardin — siendo consciente de los peligros que corría en el frentecomo su «testamento de intelectual», contiene en germen todo el desarrollo posterior de su pensamiento».

Y concluye: «La presentación de sus ideas — como aparece en varios de los escritos aquí publicados- es lírica, no exenta de exaltación: «Expongo ante todo unas consideraciones ardientes», escribe el padre Teilhard. Será por tanto en sus escritos posteriores donde habrá que buscar la forma definitiva de su pensamiento».

La estructura del texto es simple: tras una introducción, divide su exposición en cuatro capítulos, cada uno de ellos con epígrafes:

Capítulo I: El despertar cósmico. Con tres apartados: A. La visión. B. La sensación. C. La llamada.

16 Esta presentación no está firmada. Es discutible quien pudo ser el autor. Lo más probable es que fuera su secretaria, Jeanne-Marie Mortier, recogiendo las ideas de Margarita Teillard Chambon. 
Capítulo II: La comunión con la Tierra. Con dos apartados: A. La tentación de la Materia. B. Hacia el Superhombre.

Capítulo III: La comunión con Dios. Con tres apartados: A. El mundo de las almas. B. El Cuerpo de Cristo. C. El escándalo del Reino de Dios.

Capítulo IV: La comunión con Dios a través de la Tierra. Con dos apartados: A. El Cristo Cósmico. B. La Santa Evolución.

\section{La introducción de «La Vida cósmica»}

Muy probablemente, la introducción del ensayo «La Vida cósmica» - por el estilo más maduro y elaborado- pudo ser escrita con posterioridad al texto completo. Esta Introducción (que en la edición francesa y en la española tiene tipografía cursiva ${ }^{17}$ es una síntesis de las ideas principales desarrolladas más adelante y pretende introducir a lector en los objetivos de su reflexión: «Escribo estas líneas movido por la exuberancia que muestra la vida y por la necesidad de vivir; - deseo manifestar una visión apasionada de la Tierra, y para buscar una solución a las dudas sobre mi acción-; escribo porque amo al Universo, a sus energías, a sus secretos, a sus esperanzas, y porque, al mismo tiempo, estoy entregado a Dios, el único Origen, la única Salida, el único Término. Yo quiero dejar libre aquí mis sentimientos de mi amor hacia la materia y hacia la vida, y armonizar todo esto, si fuera posible, con la adoración hacia la Divinidad, que es la única absoluta y definitiva».

Y expone su hipótesis: «Yo parto de este hecho inicial, fundamental: que cada uno de nosotros, lo quiera o no, se encuentra enlazado a todo lo que le rodea por todas sus fibras materiales, orgánicas, psíquicas. No sólo se halla atrapado

17 Para esta nueva edición de La Vida cósmica, hemos tenido muy en cuenta las correcciones aportadas por el padre Teilhard durante la transcripción de la copia del manuscrito que hizo posteriormente por indicación de Marcel Légaut. De ahí las modificaciones ligeras que podrá advertir el lector. (Nota de los Editores) [Esta nota falta en la edición española de Taurus] Marcel Légaut (París, 1900 - Aviñón, 1990) fue doctor en matemáticas por la Escuela Normal Superior en 1925, y catedrático en diversas Facultades, entre ellas, Rennes y Lyon, hasta 1943. Movilizado en 1939 con el grado de teniente, su destino fue el mando de un batallón antiaéreo de quinientos hombres. A causa de su dificultad para el mando directo, se le destinó después al Estado Mayor del $3^{\text {er }}$ Ejército del Aire. En ambos destinos Légaut constató la desmoralización de la tropa y de los oficiales, así como las carencias de su propio carácter, efecto, en parte, de las carencias de su formación, lo cual puso en marcha un cambio fundamental en su vida. Dispuesto a afrontar sus propias carencias como adulto (falta de capacidad de riesgo y de decisión, con la consiguiente falta de autoridad moral en el mando), Légaut, al terminar la guerra, decidió no volver a enseñar ni a vivir como antes. Por eso, tras la capitulación de 1940, logró alternar, él y sus alumnos, el estudio de las matemáticas y el trabajo campesino, gracias a que el primer gobierno de Vichy toleró el proyecto... pero sólo por tres años. En 1943, Légaut decidió abandonar la Universidad, colgar los libros, dejar de ser catedrático y continuar, con su mujer, en Les Granges de Lèsches-en-Diois, trabajando como pastor de alta montaña. Aunque su relación con Teilhard no está muy estudiada, parece ser que mantuvieron una estrecha relación. Ver:

http://www.marcellegaut.org/?id=asociacion\&tit=Asociacion 
en una red, sino que se ve arrastrado por la corriente de un río. Por todas partes a nuestro alrededor no hay más que enlaces y corrientes. Nos encadenan mil determinismos, pesan sobre nuestro presente mil herencias, mil afinidades padecidas nos dislocan y nos acosan hacia un fin ignorado. En medio de todas estas fuerzas que interfieren, el individuo no aparece más que como un centro ${ }^{18}$ imperceptible, un punto de vista que ve, un centro de repulsión y de atracción que siente, que busca y que da bandazos, que escoge entre las innumerables energías que a través de él irradian, que busca y que confunde, que torna sobre sí y se orienta para captar más o menos, y en sentidos diversos, la atmósfera activa que le baña y en la que él es un punto singular y consciente....»

Y prosigue: "Y así es la condición exterior que nos ha sido dada. Nos hallamos, por así decirlo, mucho más fuera de nosotros, en el tiempo y en el espacio, que dentro de nosotros mismos, desde el instante en que vivimos: la persona, la mónada ${ }^{19}$ humana, como toda mónada es esencialmente cósmica » ${ }^{20}$.

Y con un lenguaje cercano al de los gnósticos, prosigue: «Mucho antes de que la reflexión, la ciencia, la historia, las necesidades sociales experimentadas, vengan a precisar en nosotros la conciencia de ese inmenso dominio del «nosotros que se encuentra fuera de nosotros» y del «nosotros que se halla en

18 El concepto de «centro» es importante en Teilhard. El «centro» no es un punto estático que ocupe una cierta situación en el espacio, sino un foco dinámico de unión que aparece en una cierta etapa de la evolución (la Vida) y es susceptible de centrarse cada vez más. La «centración» es el proceso general del ser mediante el cual el «ser» se repliega sobre sí mismo, se interioriza y se unifica. Es también el primer estadio de la dialéctica existencial de la dicha y primera etapa de toda vida espiritual (la unificación de nosotros mismos en el corazón de nosotros mismos, lo que constituye la primera condición de nuestra propia entrega, y por ello, precisamente de una unificación superior) Ver: Claude Cuénot, Nuevo Léxico de Teilhard de Chardin, 1968, Taurus, Madrid, 1970.

19 Mónada, en Teilhard, tiene un sentido preciso en tres sentidos: 1) la individualidad humana en tanto que elemento de un todo; 2) la unanimidad de las mónadas humanas en tanto que constituyen este todo individualizado que integra la Gran Mónada, el primer esbozo de la noosfera en forma de evocación poética, en la que el disco lunar simboliza la totalidad humana unificada; 3) el centro supremo de energía personalizante. La mónada teilhardiana, a diferencia de la mónada de Leibniz, se halla abierta al cosmos y al Otro, y no está regida por una armonía preestablecida (Claude Cuénot, Nuevo Léxico de Teilhard de Chardin, 1968, Taurus, Madrid, 1970) Conservamos en el texto la peculiaridad teilhardiana de escribir con letra mayúscula muchos sustantivos que para él tienen particular relevancia: Materia, Multitud, Espíritu, Hombre.

20 Para Teilhard, «cósmico» designa, por una parte, al Universo tomado como un todo formando en dimensión evolutiva una primera etapa de la organización de lo múltiple hacia la emergencia de lo humano; por otra parte, un poder de aprehender la unidad del mundo que constituye uno de los sentidos del espíritu, el sentido cósmico. El sentido cósmico es la intuición que nos pone en contacto con la totalidad del Universo y nos hace percibir la unidad bajo la multiplicidad. Dice en La Activación de la Energía: "Si bien, todavía velado, o dormido, en muchos hombres me parece que ese sentido cósmico de lo Uno y del Todo es la forma a la vez más primitiva y más progresiva de la energía psíquica en la que poco a poco se transforman a nuestro alrededor las otras energías del Mundo». En «Para ver las cosas con claridad» (25 julio 1950) (CLaude Cuénot, Nuevo Léxico de Teilhard de Chardin, 1968, 1970). 
nosotros a pesar de nosotros», una llamada secreta, íntima, que dilata nuestro egoísmo, nos advierte de que somos, en virtud de nuestras almas inmortales, los centros innumerables de una misma esfera, identificados [idénticos] mediante todo lo que no sea su incomunicable psiquismo, - los elementos encadenados de una misma curva que se prolonga por delante y por detrás de nosotros. Por una innata y oscura afinidad, por una necesidad inmanente de palpar lo estable y lo absoluto, sentimos que en nuestro corazón se incuba o irrumpe bruscamente el deseo de transformar el aislamiento que nos concentra sobre nosotros mismos en una existencia más amplia, en una unidad de orden superior, haciéndonos capaces de poder participar en la Totalidad de lo que nos arrastra y nos embarga. La aspiración panteísta hacia la fusión de todos en todo ${ }^{21}$, tal es el aspecto inmanente de nuestra naturaleza cósmica, la una como prueba de la otra, tan innegable ésta para nuestras voluntades como aquélla para nuestras inteligencias,... pero sólo para los que miran, sólo para los que sienten».

No deja de haber un ligero deseo apologético, posiblemente fruto de su contacto con hombres descreídos en el frente de batalla: «Hacer mirar, hacer sentir, - vengarme, mediante una profesión de fe inflamada en la fecundidad y el valor del Mundo, de los que sonríen y menean la cabeza cuando se les habla de una nostalgia vaga por algo oculto en nosotros que nos sobrepasa y nos culmina, triunfar incluso sobre esos hombres mostrándoles hasta la saciedad que su envanecida individualidad no es más que una brizna de paja en el seno de las energías que pretenden ignorar, o de las que se burlan si les hablamos de levantar un templo en su honor: esa es mi primera intención. Es preciso, si el ser Humano quiere alcanzarse a sí mismo, que despierte a la conciencia de sus infinitas prolongaciones, a sus deberes, a su embriaguez. ¡Es necesario que el ser Humano (dando de lado a todas las ilusiones de un individualismo estrecho), amplíe su corazón a la medida del Universo, y arrebatado por el vértigo de su nueva grandeza, no pueda menos de creerse en posesión de lo divino, de Dios mismo, o que se crea el forjador de la Divinidad!»

Teilhard expone con claridad los objetivos de su reflexión: «No pretendo hacer directamente ni ciencia, ni filosofía, ni, mucho menos, apologética. Expongo ante todo unas consideraciones ardientes. Casi sin una actitud de condena por mi parte, desde luego, veré, para comenzar, cómo reina en el pensamiento y en las pasiones humanas la crisis, compañera de todo despertar; como simple observador, ante todo, contemplaré nacer y desenvolverse en el secreto de

21 La continuación (capítulo 2) y un número considerable de escritos posteriores (en particular, "Panteísmo y cristianismo», 1923 [publicado en Como yo Creo, edición Taurus, 1970, páginas 65-84], precisarán su sentido al distinguir un doble significado de la palabra «panteísmo» y de la aspiración que traduce; el panteísmo rechazado es el que habitualmente se designa bajo este término, y el admitido es el que Teilhard expone. En «El Elemento universal» [de febrero de 1919, publicado en Escritos del tiempo de guerra, edición Taurus, 1967, páginas 417-434], en El Medio Divino (página 122 de la 5ª edición española, 1966) y en otras partes rechaza simplemente «el panteísmo». 
las almas o en medio del tumulto de las multitudes, la tentación cósmica; veré doblarse las frentes ante el becerro de oro y al incienso ascender hacia la montaña del orgullo humano. Casi sin pruebas, también, pero fortalecido con sus propias armonías con el Resto y con sus propias correspondencias, yo dejaré que, en aparente oposición con los sueños de la Tierra, que él viene a completar y corregir, surja el inefable Cosmos de la materia y de la Vida nueva, el Cuerpo de Cristo, real y místico, unidad y miríada, mónada y pléyade».

Se trasluce también su sensibilidad de poeta y místico: "Y, semejante a quienes acunan melodías sucesivas y diversas, dejaré, en múltiples sentidos, hacia el éter inicial, hacia el superhombre, hasta el Hombre-Dios, que cante y grite mi vida... hacia abajo, hacia arriba, por encima...»

Y desde estos sentimientos, expresa sus dudas, el hilo de sus reflexiones en búsqueda de coherencia existencial: «Porque, en definitiva, ¿es que para ser cristiano hay que renunciar a ser humano, humano en el sentido amplio y profundo de la palabra, desesperada y apasionadamente humano? ¿Habrá de ser preciso para seguir a Jesús y tener parte en su cuerpo celeste, renunciar a la esperanza de que palpamos y preparamos algo de lo absoluto cada vez que, bajo los golpes de nuestro esfuerzo, llega a ser dominado un poco más de determinismo, se adquiere un poco más de verdad, se realiza un poco más de progreso? ¿Es necesario, para hallarse unido a Cristo, desinteresarse de la marcha propia de este Cosmos embriagador y cruel que nos sostiene y que se alumbra en cada una de nuestras conciencias? Y una operación como ésa ¿no corre el riesgo de convertir, a quienes la realizaran en sí mismos, en mutilados, en tibios, en debilitados? He aquí el problema de vida en el que entran en conflicto inevitablemente, dentro de un corazón de cristiano, la fe divina que sostiene sus esperanzas individuales y la pasión terrestre que constituye la savia de todo el esfuerzo humano».

Y expone sus convicciones: «Es mi convicción más querida que el desinterés por todo lo que constituye lo agradable y el interés más noble de nuestra vida natural no puede ser la base de nuestros crecimientos sobrenaturales. El cristiano, si comprende bien la obra inefable que se cumple a su alrededor y por medio de él en «toda» la naturaleza, tiene que caer en la cuenta de que los impulsos y los arrebatos suscitados en él por el «despertar cósmico» pueden ser considerados por él, no solamente en su forma traspuesta sobre un Ideal divino, sino también en el tuétano de sus objetos más materiales y más terrestres: para ello le basta con penetrarse del valor beatificante y de las esperanzas eternas de la santa Evolución...

Para concluir: «Y he aquí la palabra que quiero hacer escuchar por encima de todo: la de la reconciliación de Dios y del Mundo, porque es ella la que reconcilia a Dios y al mundo. Estas páginas a las que he querido transmitir, con lo mejor de mi reflexión sobre las cosas, la solución leal por medio de la cual se ha equilibrado y unificado mi vida interior, se las dedico a aquellos que desconfían de Jesús, porque sospechan que pretende desflorar, a sus ojos, el rostro irrevocablemente amado de la tierra, a aquellos también que, por amor a Jesús, se constriñen a ignorar aquello de que su alma desborda, a aquellos en 
fin, que, por no haber logrado hacer coincidir el Dios de su fe y el Dios de sus más ennoblecedores trabajos, se fatigan y se impacientan en medio de una vida dislocada por esfuerzos oblicuos. 24 de marzo de 1916. Nieuport»

Hemos querido reproducir casi completo el texto de la Introducción que hace Teilhard a «La Vida cósmica» porque refleja de modo fehaciente sus preocupaciones más íntimas, Aquellas que se irán desvelando, precisando y respondiendo a lo largo de casi medio siglo de reflexión.

\section{Contenidos de los capítulos}

Tras esta introducción, que hemos reproducido casi íntegra por su interés, Teilhard, como ya se ha indicado más arriba, estructura el hilo de sus reflexiones a lo largo de cuatro capítulos que se presentan brevemente y se acompañan con los textos que han parecido más expresivos.

\section{Capítulo I: el despertar cósmico}

la expresión «despertar cósmico» le pudo ser sugerida a Teilhard la lectura de algunos autores gnósticos a los que tuvo acceso en las trincheras de Francia donde ejercía de camillero ${ }^{22}$. Tal vez quiere expresar su situación interior en la que algo nuevo se expande en el interior de su corazón. Visión, sensación y llamada son los tres epígrafes de este primer capítulo. En ese estado interior de «darse cuenta», percibe, se deja inundar de sensaciones y responde generoso a una llamada interior.

\section{a. La visión}

¿Qué es lo que «ve» Teilhard con los ojos interiores? Tres niveles de profundidad en la visión: la visión de una realidad material que presenta una gran diversidad de formas y una gran cantidad de individuos de cada forma (lo

22 En Internet (consulta de 22 de abril de 2015) hemos encontrado 11.300 entradas en castellano sobre el tema del «despertar cósmico» siempre relacionadas con grupos esotéricos, gnósticos o de espiritualidades orientales. Ver, por ejemplo,

http://www.asociacionthimetis.com/index.php/el-despertar-cosmico/el-despertarcosmico. Definen ese «despertar» de modos diversos: «El despertar cósmico es el estado de conciencia que se logra cuando el individuo integra en su vida todos los valores morales, emocionales y espirituales, y sabe cómo utilizarlos para que produzcan el efecto deseado en su vida. La conciencia cósmica es la comprensión de que el ser humano pueda desarrollarse, ampliando su libre albedrío a la esfera de lo espiritual, como entidad divina no supeditada a las limitaciones de la materia. El despertar cósmico es ese estado de percatación en el cual se es consciente de que. aunque el cuerpo físico pueda estar circunscrito a actuar en el espacio, el Yo Superior vibra en otra textura. Es decir, el ser es consciente de su existencia multidimensional y de su naturaleza inmortal que reúne los códigos eternos de su sublime descendencia como parte de la Divinidad, recreándose en los planos de la materia. Nada es diferente del Padre Divino y, simultáneamente, todo lo es». 
que llama «La Multitud»). El segundo nivel es el de la Unidad. En este escrito, Teilhard está fascinado por el concepto físico de Éter, del que se desprenderá años más tarde - como veremos - al ser desechado por la física einsteniana. Pero le será útil para expresar el tejido místico del universo, la continuidad sin rajaduras. El tercer nivel de visión es el de la Unidad de la Vida. La expresión de un orden cósmico que se supera a sí mismo y que evoluciona.

Reproducimos algunos de los textos más significativos:

«La visión fundamental es la de la pluralidad y la de la multitud; la multitud que nos envuelve y la multitud que nos constituye; la que se agita a nuestro alrededor y la que se esconde dentro de nosotros (...). A los ojos del sabio que mira, la continuidad aparente de los seres materiales, o su partición en fragmentos artificiales y accidentales, ceden su puesto al hormigueo innumerable de las mónadas naturalmente distintas. Y sin embargo, estas mónadas no son unas hendiduras en el tejido inconsútil del Universo, porque, en su reposo y en su acción, en su textura y en su devenir, bajo los vínculos que las unen o las jerarquizan y las corrientes que las arrastran, siguen siendo - ése es el misterio del Cosmos y el secreto de la Materia- una misma cosa».

Y más adelante: «(...) La Vida, como acabamos de decir, prolonga de alguna manera la materia: conserva de ella, junto con los elementos, algunos hábitos; incluso puede, como veremos, copiarla e imitarla al funcionar mecánicamente. Pero se distingue más todavía por el modo particular de involución conforme al cual nacen bajo su influencia las mónadas, también por el sentido general de la corriente de perfección creciente al hilo del cual la Vida los arrastra. A través y a favor de la Materia que se deshace, la Vida asciende acompañando al trabajo de organización exterior que lleva a cabo a través de los individuos, de un repliegue interno especial gracias al cual aparece, en el corazón de la Materia, una figura cada vez más consciente. Ahora bien, nada une los centros como esta génesis común que los asocia en su estructura y en su destino. Releamos más bien sobre esas páginas de piedra la historia de la transformación de los organismos vivientes...»

\section{b. La sensación}

En el proceso de toma de conciencia de la realidad que nos rodea, Teilhard se deja seducir por la huella amorosa que esa visión deja en su corazón: «Descendamos hacia el interior de nosotros mismos, vuelvo a decir, y nos quedaremos aterrados de encontrar allí, por debajo del ser Humano de las relaciones y la reflexión superficiales, un desconocido, apenas desprendido del inconsciente, todavía medio adormecido, a falta de excitante apropiado,cuyos rasgos, en la penumbra, parecen tener que ver con la figura del Mundo (...). No, no hay choque tan brutal ni roce de caricia que sean comparables a la vehemencia y a la sugestión de esta toma de contacto de nuestro individuo con el Universo, cuando bajo la banalidad de nuestras experiencias más familiares, advertimos súbitamente, poseídos de un terror sagrado, que el inmenso Cosmos aflora en nosotros». 


\section{c. La llamada}

La visión interior del mundo diverso y en deriva cósmica y la sensación interior del inmenso Cosmos que aflora en nosotros, se siente llamado a salir de sí mismo (de su ensimismamiento) y lanzarse a la construcción de lo que le es dado. Y concluye: «He aquí la palabra liberadora: no basta al ser Humano, venciendo su egoísmo, vivir socialmente. Tiene necesidad de vivir con todo su ser, en unión con el conjunto del Mundo que le sostiene, —cósmicamente. Hay una savia o un Espíritu de las cosas más íntima que el alma de los individuos, más vasta que la comunidad humana; hay algo absoluto que nos atrae y que se oculta. Y para contemplar su figura, para responder a su llamada y comprender su sentido, para aprender a vivir más, nos es necesario zambullimos en la vasta corriente de las cosas y ver adónde nos llevan sus olas».

\section{Capitulo II. La Comunión con la tierra}

Llamado a «zambullimos en la vasta corriente de las cosas y ver adónde nos llevan sus olas», Teilhard se siente llamado a vivir intensamente la realidad material, el trabajo, la existencia humana para desde ahí —como veremosirrumpir en niveles superiores de conciencia ${ }^{23}$.

\section{a. La tentación de la materia}

Veamos algunos textos más significativos: «El primer impulso del ser Humano que, habiéndose abierto a la conciencia del Cosmos, ha realizado el ademán de arrojarse en él es el de dejarse mecer como un niño por la gran Madre entre cuyos brazos acaba de despertarse. En esta actitud de abandono - simple emoción estética en unos, regla de vida práctica, sistema de pensamiento y aun de religión en otros- está la raíz común de todos los panteísmos paganos». (...) «Y ¿por qué no habría yo, de hecho, de adorarla a ella, [a la Materia], a la Estable, a la Grande, a la Rica, a la Madre, a la Divina? ¿Acaso no es eterna e inmensa a su modo? ¿Acaso nuestra imaginación no se niega a concebir

23 El concepto de "comunión con la tierra» ha sido frecuentemente utilizado por escritores de tendencias gnósticas. Los seguidores de la llamada ecología espiritual, el ecobudismo y seguidores de la filosofía sufí aluden a Teilhard con frecuencia (ver http://www. goldensufi.org/s_a_entrevista_ecologia_espiritual.html) Este texto de uno de sus seguidores es significativo: «En Occidente, en las últimas décadas hemos tenido un acceso cada vez mayor a las enseñanzas y prácticas espirituales, por ejemplo, la meditación y el canto sagrado. Nutren nuestra parte sagrada con luz, energía o presencia. Pero nuestra alma también necesita ser alimentada por el mundo exterior: se ha encarnado en este mundo con el fin de tener ciertas experiencias significativas en la vida. En El Fenómeno Humano, Teilhard de Chardin escribió que «No somos seres humanos que tenemos una experiencia espiritual, somos seres espirituales que tenemos una experiencia humana». Desde el principio de los tiempos, esta relación sagrada con la vida ha sido entendida por todas las culturas indígenas. Sus rituales de la vida cotidiana eran siempre sagrados, y establecían y mantenían una relación sagrada con la creación que los nutría». 
su ausencia, lo mismo en el lejano extremo del espacio que en el retroceso indefinido de los siglos? ¿No es ella la Sustancia única y universal, la fluidez etérea que todas las cosas que se extienden sin disminuirla ni romperla? ¿No es ella, la Terra Mater, la generadora absolutamente fecunda, la que contiene las semillas de toda vida y el alimento de toda alegría? ¿No es ella a la vez el origen común de los Seres y el único Término que podemos imaginar, la Esencia primitiva e indestructible de donde todo emana y adonde todo vuelve, el punto de partida de todo crecimiento y el límite de toda dispersión? Todos estos distintos atributos que la filosofía espiritualista ${ }^{24}$ proyecta fuera del Universo, ¿no sería más bien en el polo opuesto, en las profundidades del Mundo, donde se realizan y tienen que ser alcanzados, en el seno de la Materia divina?

Y se deja seducir por la fascinación de la realidad viviente: «(...) ¡La Vida! ¿A dónde acudiríamos en ciertas horas de extrema turbación sino al último criterio, a la suprema decisión de su logro y de sus caminos? Cuando vacilan todas las certidumbres, balbucean todas las palabras, se vuelven sospechosos todos los principios, ¿a qué última creencia asir nuestra existencia interior a la deriva sino a ésta: que existe un sentido absoluto de crecimiento, en el que nuestro deber y nuestra felicidad consisten, al que nos debemos conformar, ya

${ }^{24}$ Al referirse a la filosofía espiritualista» se entiende la filosofía del gnosticismo, del espiritismo. Este es uno de los temas teilhardianos más delicados y controvertidos: la influencia sobre Teilhard del pensamiento esotérico. La New Age ha abundado en ello. Téngase en cuenta que Teilhard en esta época leyó uno de los libros del filósofo gnóstico francés Edouard Schuré (1841-1929). En una de las últimas cartas enviadas durante la Primera Guerra Mundial desde el frente de guerra a su hermana Marguerite, cartas que quedaron recopiladas en lo que hoy se conoce con el título «Génesis de un pensamiento»; Cartas (19141919), (pág.296-297) en donde le señala: «El viaje ha sido excelente y lo he pasado meditando en todo lo que hemos dicho y leyendo a Schuré (Los grandes Iniciados). La introducción me ha entusiasmado. Por el contrario, Rama me parece terriblemente imaginativo y de una ciencia más que superada. Pero como tú has advertido es el alma de Schuré lo interesante, tanto al menos como las de sus iniciados. (4 de noviembre de 1918)» Schuré en detalle nos muestra la época en que vivió cada Maestro, las secretas Iniciaciones que el círculo interno. Parece ser que Teilhard leyó Los grandes iniciados (edición española, Editora y Distribuidora Tomo II, México 1996). Hay un párrafo en ese libro que recuerda mucho a Teilhard: He aquí el texto: «La evolución material y la evolución espiritual del mundo son dos movimientos inversos, pero paralelos y concordantes en toda la escala del ser. El uno, sólo por el otro se explica, y, vistos en conjunto, explican el mundo. La evolución material representa la manifestación de Dios en la materia por el alma del mundo que la trabaja. La evolución espiritual representa la elaboración de la conciencia en las mónadas individuales y sus tentativas de unirse, a través del ciclo de vidas, con el espíritu divino de que ellas emanan. Ver el universo desde el punto de vista físico, o desde el punto de vista espiritual, no es considerar un objeto diferente, es contemplar el mundo desde los dos extremos opuestos. Desde el punto de vista terrestre, la explicación racional del mundo debe comenzar por la evolución material, puesto que por este lado la vemos; pero haciéndonos ver el trabajo del Espíritu universal en la materia y proseguir el desenvolvimiento de las mónadas individuales, ella conduce insensiblemente al punto de vista espiritual y nos hace pasar del exterior al interior de las cosas, del revés del mundo a su lado profundo.» Ver a este respecto: SEQueIros, L. (EDitor) Maldito Teilhard. Pierre Teilhard de Chardin y la New Age. Bubok ediciones, 2014. Accesible en digital en http:// metanexus.bubok.es 
que la vida camina en ese sentido, en la dirección más recta? (...) En el pasmo primero de mi inmersión en el seno del Universo yo me dejaba deslizar sin resistencia hacia el disfrute perezoso y el Nirvana... Como el buceador que vuelve en sí y domina su inercia, yo debo ahora, con un vigoroso esfuerzo, invertir mi dirección y volver a ascender hacia las zonas superiores. La auténtica llamada del Cosmos es una invitación a venir a participar conscientemente en la gran tarea que se lleva a cabo en su seno: no es dejándose llevar por la corriente de las cosas como llegaremos a unirnos a su alma única, sino luchando con ellas, hacia un Término que ha de venir».

\section{b. Hacia el superhombre}

Del seno de la vida surge en pensamiento, la capacidad de ser conscientes de nosotros mismo. Todavía Teilhard no ha incorporado en su vocabulario el concepto de noosfera que aparece posteriormente. Pero sí se deja fascinar por el ser humano. Y percibe en el horizonte hacia donde se encamina la humanidad como un todo. Y en ese camino hacia lo que aquí llama Superhombre ${ }^{25}$. Este camino de ascensión hacia una sociedad del futuro se realiza a lo largo de varias etapas que describe Teilhard: el dominio del Universo, la segregación de la Humanidad, la liberación del Espíritu, la Paz que el Mundo da y la queja del alma.

Veamos algunos textos más significativos:

«Primera etapa. El dominio del Universo. (...)Sostenido por la esperanza inmensa de elevarse indefinidamente, de conquistar su propia felicidad, y tomando un punto de apoyo sobre la Materia, el ser Humano, con un fervor renovado, se entrega al estudio apasionado de los poderes del Universo y se absorbe en la búsqueda del gran Secreto; su faena austera queda envuelta en los reflejos místicos que iluminaron el rostro ansioso de los alquimistas, que aureolaron la frente de los magos, que divinizaron el ademán de Prometeo, y que ante cada nueva propiedad que se manifiesta a sus ojos - como un nuevo día abierto sobre la Tierra prometida-, el sabio está a punto de arrodillarse, como ante la revelación de un atributo divino...»

Segunda etapa. La segregación de la humanidad.

La palabra «segregación» tiene para Teilhard un significado especial. Es un término del que hace un uso geológico y biológico, y por extensión, espiritual. En el plano científico - según Cuénot- designa un proceso de separación respecto de un todo. En el plano ontológico y religioso designa el proceso mediante el cual uno o varios elementos dejan de participar en el movimiento

25 El Superhombre de Teilhard no tiene nada que ver con el Superhombre de Nietsche. Para Teilhard es la humanidad toda unificada y plenificada que construye el tejido misterioso de un Cosmos más humanizado. Ver: http://galetel.webcindario.com/id42.htm y http:// www.researchgate.net/publication/31803623_EL_SUPERHOMBRE_DE_NIETZSCHE_A_ TEILHARD_DE_CHARDIN_JULES_CHAIX-RUX_TR._DOMINGO_RIERA_DUCH 
de unión que constituye lo real, y por lo mismo tienden a la nada. Así escribe: «El movimiento que agrega el Universo a Cristo es en realidad una segregación. Una parte de Materia mala, definitivamente eliminada, formará el desecho irreductible de la operación salvífica universal» («Los nombres de la Materia» (1919). Escritos del tiempo de guerra. p. 449).

Este texto de «La Vida cósmica» puede ser expresivo: «En el esfuerzo y por el esfuerzo mismo que desarrolla para adueñarse de la Materia y explotarla, el ser Humano afirma su trascendencia relativa, su superioridad sobre el resto de las Cosas. Se desprende de la confusa turbamulta de las mónadas; aprende a interesarse por sí mismo, a considerarse mejor, a concentrar sobre su ser y sus progresos el amor y el interés que había dejado extenderse con excesiva uniformidad sobre el conjunto del Universo. (..)»

Y concluye: «De hecho son numerosos los fieles de la fe en el progreso humano. Puede uno burlarse de su candor, oponerles el espectáculo desconcertante de las luchas y maldades humanas. Seguirán obstinados en su esperanza. Aceptar que la humanidad va a la deriva y aborta, admitir que no subsiste en ella ninguna Promesa, ¿no equivaldría esto a renunciar a la percepción de algo absoluto en el Universo, a reconocer que el Cosmos se halla vacío, su llamada es engañosa, la Vida impotente y falaz? No. Una trampa de esa especie no es conciliable con las certezas más profundas del ser. Bajo el esfuerzo combinado de la ciencia, de la moralidad, de la asociación, se está formando una Superhumanidad, cuya fisonomía, tal vez, tendrá que ser buscada por el lado del Espíritu».

Teilhard avanza un paso más en este proceso de ascenso hacia el ser humano total y global, cósmico. Lo que llama el Superhombre:

\section{«Tercera etapa. La liberación del Espíritu.}

Para Teilhard, en el proceso de humanización hay una progresiva expansión de las dimensiones más profundamente humanas, intelectuales y espirituales. La Materia es superada por sí misma para dejar expandir el Espíritu aprisionado en los límites del espacio y del tiempo. Escribe:

«Y así, cuando las decisiones del pensamiento vienen a añadirse a las insinuaciones de la experiencia, entrevemos cada vez con más claridad, como posible, la espiritualización del Universo. Por medio de un adiestramiento mental sui generis, combinado con una mejor organización de las relaciones entre mónadas, el individuo puede colaborar a conseguir que la conciencia y la agilidad refluyan en la multitud atómica y en la multitud humana, en la Materia inorgánica y viviente, y en la Materia social. Tal es la tarea cósmica, —que conduce a la Humanidad a la liberación y a la felicidad» (....) «Cuándo reinará por todas partes la armonía final, después de haber suprimido los choques y los desgarros, después de haber corregido las propensiones nefastas y los contactos prohibidos, llevando al fondo de todas las cosas la luz; entonces ni el dolor, ni la maldad, ni las tinieblas, desfigurarán ya el Cosmos regenerado. Todo lo que había venido siendo embrutecimiento secundario, relaciones falsas o culpables, todo el mal físico y moral, toda la parte mala del Mundo, habrán desaparecido; el resto habrá florecido de nuevo, el Espíritu habrá absorbido la Materia». 
«Cuarta etapa. La Paz que el Mundo da.

La cuarta etapa de este camino de autoliberación interior del Espíritu humano, se consigue cuando la expansión de las dimensiones más íntimas de la humanidad se derrama y construye una nueva sociedad en paz. Este texto puede ser clarificador:

«Llegado a este punto supremo de depuración de sus perspectivas y de expansión de sus anhelos, el ser Humano se detiene, y se vuelve sobre sí mismo. Debido al cansancio de su inestabilidad y de su pequeñez, ha abandonado su morada para correr en busca del Elemento absoluto y adorable del Universo. Ahora que ha encontrado un sentido a la Vida; ahora que ha descubierto la Divinidad a cuyo honor su ser ardía oscuramente por consagrarse, enriquecido con sus descubrimientos, el ser Humano vuelve a entrar en el secreto refugio de su corazón y mira».

"Quinta etapa. La queja del alma.

¿De qué queja habla Teilhard? Este texto puede clarificarlo:

«Pero he aquí que en el mismo momento en que me congratulaba de haber encontrado por fin una base inquebrantable de impasibilidad, un último fin que habría de calmar y polarizar todas mis inquietas aspiraciones, he escuchado una queja prolongada que se elevaba dentro de mí, el llanto de mi alma sacrificada, que lloraba las esperanzas que había puesto en sí misma y que ya no existen (...).

Y concluye: "Que descienda, por tanto, del Cielo, si es que no puede ser escuchada en la Tierra, la palabra que, sintetizando los ardores del alma y las exigencias del Cosmos, habrá de revelarnos por qué misteriosa organización de los extremos pueden las aspiraciones individuales consumarse en la realización del todo».

\section{Capitulo III. La Comunión con Dios}

La Comunión con la tierra permite el acceso a la plena comunión con Dios. En el continuum evolutivo del cosmos que se desarrolla dinámicamente todo asciende y converge hacia una única meta: Dios. Todavía no ha elaborado uno de sus conceptos más expresivos: el punto Omega. Pero ya se intuye, sin nombrarlo. Tres son los apartados que contienen el hilo de sus pensamientos: el mundo de las almas, el Cuerpo de Cristo y el escándalo del Reino de Dios.

\section{a. El mundo de las almas (...)}

«Para celebrar el entusiasmo de esta unión y de esta unificación, al corazón y a los labios les están permitidos los términos más apasionados del panteísmo y hasta el éxtasis; además, ya que la Cosa universal de la que todo emana y a la que todo vuelve, no es lo Impersonal, lo Incognoscible y lo Inconsciente, donde el individuo se diluye y se pierde al fundirse, sino por el contrario, un Ser viviente que ama, en quien las consciencias, cuando se pierden, acaban de 
acentuarse y de iluminarse hasta las últimas posibilidades de su personalidad. Vasto y envolvente como la Materia, pero cálido e íntimo como un alma, Dios es el Centro por doquier extendido, cuya inmensidad se debe a un exceso de concentración, cuya opulenta simplicidad sintetiza un paroxismo de virtudes acumuladas. ¡Oh, la alegría inexpresable de sentirse invadido, absorbido por un Infinito no distendido e incoloro, sino viviente y luminoso, que conoce, que atrae, que ama!»

\section{b. El cuerpo de Cristo}

Esta alegría interior de sentirse absorbido por Dios se expresa en la unión con Cristo. Escribe: «La tarea única del Mundo consiste en la incorporación física de los fieles a Cristo en Dios. Ahora bien, esta obra capital se prosigue con el rigor y la armonía de una evolución natural. (...) En verdad, el Cuerpo místico de Cristo tiene que ser concebido a la manera de una Realidad física, sin atenuación alguna... Sólo con esta condición, adquieren toda su significación los grandes misterios y las grandes virtudes de la Religión, el papel mediador de Jesús, la importancia de la Comunión, el valor extraordinario de la caridad; sólo con esta condición, conserva su plena seducción sobre muchos espíritus la Persona del Salvador, su plena urgencia sobre nuestros destinos».

Y concluye con esta plegaria: «iOh, sí, Jesús, yo lo creo y quiero proclamarlo sobre los tejados y las plazas públicas, no sólo eres el Dueño exterior de las cosas y el esplendor incomunicable del Universo: más que todo esto, eres la influencia dominante que nos penetra, nos posee, nos atrae, por la médula de nuestros deseos más imperiosos y más profundos; eres el Ser cósmico que nos envuelve y nos consume en la perfección de su Unidad! Así y por eso, yo te amo por encima de todo».

\section{c. El escándalo del reino de Dios}

Es el tercer paso en este proceso de Comunión con Dios. La absorción en Dios por en Cristo cósmico conduce al compromiso con el mundo, a la cooperación en la construcción de la nueva sociedad que culminará en el Reino de Dios:

«Sin duda que me queda el recurso y el deber de cooperar al Progreso temporal del Mundo "para hacer la voluntad de Dios», "para honrar a la Iglesia», "para confundir a los incrédulos». Pero, qué fríos, lejanos e indirectos son todos estos motivos, comparados con la urgencia de los aguijones que clava la necesidad de «acertar», para "ser». Está muy bien que se me advierta que hay un precepto divino de hacer fructificar la Tierra. Pero se añade a continuación, que los frutos esperados de mi labor son en sí mismos vanos y perecederos, que, ante todo, el Mundo ha sido abandonado en mis manos, como una ardilla a su rueda, para ejercitarme en el vacío. ¿Qué llama es la que se espera de mi buena voluntad? Para que yo me entregue, ardientemente, sinceramente, al esfuerzo cósmico, para que pueda concurrir con armas iguales que a las de los Hijos de 
la Tierra, es preciso que me halle convencido, no sólo del mérito de mis obras, sino de su valor. Es preciso que crea en lo que hago... (...) Ahora bien, quiera o no quiera, yo creo en él. Creo en la ciencia, cuando trabajo en un laboratorio. Creo en algún Superhombre, cuando me entusiasmo con una guerra de culturas y considero como un favor de Dios poder arriesgar mi existencia a una muerte abominable, para hacer triunfar un ideal de civilización. Y al creer en ello, no tengo conciencia de estar renegando de mi fe en Cristo, ni de defraudar al amor absoluto con el que me he consagrado. Muy al contrario, tengo la sensación de que cuanto más solícitamente me ocupo de una Tierra más grandiosa, más pertenezco a Dios».

Tras estos tres capítulos anteriores, desembocamos en el cuarto y último: la gran Unión, la fusión de todas las cosas en Cristo y ellas en Dios.

\section{Capítulo IV. La Comunión con Dios a través de la tierra}

Dos son los puntos básicos de esta comunión: el Cristo cósmico y la Santa Evolución. Dos intuiciones que describe con gran vigor poético y místico:

\section{a. El cristo cósmico}

«Por la gracia, Jesucristo se halla unido a todas las almas santas, y como los vínculos que unen las almas con Él en una sola masa santificada desembocan en El, se reúnen en El, tienen consistencia gracias a Él, es Él quien reina, es Él quien vive; el cuerpo entero es a Él a quien pertenece. Pero las almas no son un grupo de mónadas aisladas: forman con el Universo (esto es precisamente lo que nos revela la «visión cósmica») un bloque único, cementado por la Vida y por la Materia (...) ....Y desde que Cristo nació, y que cesó de crecer, y que murió, todo ha continuado moviéndose, porque Cristo no ha acabado todavía de formarse. No ha terminado de recoger sobre sí los últimos pliegues del Vestido de carne y de amor que le forman sus fieles. El Cristo místico no ha alcanzado su pleno crecimiento, ni tampoco, por tanto, el Cristo cósmico. Uno y otro, a la vez, son y llegan a ser: y en la prolongación de este engendramiento se encuentra situado el resorte último de toda actividad creada. Por la Encarnación, que ha salvado a los hombres, ha sido transformado y santificado el Devenir mismo del Universo; Cristo es el término de la Evolución, incluso natural ${ }^{26}$, de los seres; la evolución es santa. He aquí la verdad liberadora, el remedio divinamente preparado para las inteligencias fieles, pero apasionadas, que sufren por no poder conciliar entre sí dos impulsos casi igualmente imperiosos y vitales: la fe en el Mundo y la fe en Dios».

26 Desde el momento que el Universo (la Naturaleza) es una Evolución, puede decirse, con relación a la Evolución, lo que Santo Tomás decía con relación a la Naturaleza, al hablar de lo sobrenatural: Non est aliquid naturae, sed naturae finis: no es algo de la naturaleza, sino el fin (último) de la naturaleza. Nota del Editor de las Obras de Teilhard 


\section{b. La santa evolución}

Esta expresión, que debió parecer escandalosa a sus contemporáneos, resume todo el hilo de su discurso interior:

1. La mano de Dios está sobre nosotros. "El Mundo sigue creándose, y en él, es Cristo quien lo lleva a su final». Al escuchar y comprender estas palabras, he abierto los ojos. Y me he dado cuenta, como si estuviera en un éxtasis, de que me hallaba sumergido en Dios por medio de toda la Naturaleza (...) Dios trabaja en la Vida ${ }^{27}$. La ayuda, la levanta, le da el impulso que la acosa, el apetito que la atrae, el crecimiento que la transforma. Le siento, y Le toco, y Le "veo», en la profunda corriente biológica que circula en mi alma y se la lleva consigo. Dios transparece ${ }^{28}$ y se personifica en la Humanidad. Le encuentro en mi hermano; Le oigo hablar en las órdenes superiores, y luego, de nuevo, como en una segunda zona material, Le encuentro y Lo experimento en el contacto dominador y penetrante de Su mano, Le encuentro y Lo experimento en el nivel superior de las energías colectivas y sociales.

2. La lucha con el Ángel.- Ahora bien, nosotros no somos sólo las criaturas acunadas y alimentadas por «La Madre Tierra» ${ }^{29}$.(...) Sin embargo, importa mucho, para la nitidez y la alegría de nuestra acción, que intentemos precisar algunos factores y algunas líneas de esta coincidencia. ¿Cuáles pueden ser los residuos absolutos del Cosmos, destinados a pasar al edificio celeste? ¿De qué manera puede la segregación de los elegidos en una masa santa, ser influenciada por los descubrimientos de la pura Ciencia, de la Física, de la Historia? ¿Cómo, aparte del aumento de los méritos sobrenaturales, se realiza Cristo en la Evolución? (...) Pero ¿por qué esa pusilanimidad en nuestras concepciones

27 Escribe San Ignacio en La Contemplación para Alcanzar Amor de los Ejercicios Espirituales: «[236] El tercero, considerar cómo Dios trabaja y labora por mí en todas las cosas criadas sobre la haz de la tierra.» Ver: L. SEQueIRos, El todo amar y servir. La diafanía de la divinidad en el corazón del Universo. Bubok ediciones, 2013.

28 La palabra «transparait» de Teilhard la hemos traducido por «transparece», se muestra transparente, se hace diáfano. Este concepto aparece también en La Misa sobre el Mundo de Teilhard. Y la hemos interpretado como una alusión al episodio de la Transfiguración del Señor. Ver la nota anterior.

29 En griego en el original: Gaia metér. La madre Gea, la Tierra. En «Escritos esenciales» se resalta este texto. Ver:

https://books.google.es/books?id=ie85XuDt7nwC\&pg=PA59\&lpg=PA59\&dq=\%22Gaia+ meter\%22\&source=bl\&ots=SuJaHXtVn1\&sig=vstDsbvlUA4LN2XHpR55yKgVIgQ\&hl=es419\&sa $=X \&$ ei $=i h Q Z V f b g D s O t U b H y g N g G \& v e d=0 C D E Q 6 A E w B w \# v=$ onepage $\& q=\% 22 \mathrm{Ga}$ ia\%20meter\%22\&f=false "Teilhard de Chardin passed away a full ten years before James Lovelock ever proposed the "Gaia Hypothesis» which suggests that the Earth is actually a living being, a collosal biological super-system. Yet Chardin's writings clearly reflect the sense of the Earth as having its own autonomous personality, and being the prime center and director of our future - a strange attractor, if you will - that will be the guiding force for the synthesis of humankind». http://www.gaiamind.com/Teilhard.html 
y con qué derecho? Toda la economía de la Iglesia, con sus dogmas y sus sacramentos, nos enseña el respeto y el valor de la Materia. Cristo quiso y tuvo que asumir una carne auténtica. Él santifica nuestra carne mediante un contacto especial. De esa manera, prepara físicamente la Resurrección.

3. El Sentido de la Cruz. La lucha es ardua. La Tierra gime en el parto de Cristo. Omnis creatura ingemiscit et parturit ${ }^{30}$. Como un carromato que rechina y traquetea, el Progreso avanza dolorosamente, en medio de magulladuras y llantos (...) El cristiano siente el dolor como los demás. Como los demás, tiene que esforzarse por disminuirlo y dulcificarlo, no sólo por medio de oraciones de súplica, sino mediante los esfuerzos de una Ciencia industriosa y segura de sí misma. Pero cuando llega el momento en que el dolor se impone, el cristiano la utiliza [la ciencia]. En virtud de una maravillosa compensación, el mal físico, humildemente soportado, consume el mal moral. Conforme a leyes psicológicas definibles, depura el alma, la estimula y la hace desprenderse. En fin, como si fuera un sacramento, opera una misteriosa unión entre el fiel y Cristo que sufre».

4. El Lugar del Infierno en esta síntesis. Cristo, al insertarse en la Evolución, ha perfeccionado y fecundado hasta el extremo sus recursos y su mecanismo. Todo, rigurosamente todo, incluso el dolor y la desgracia, puede servir, en el orden de la salvación, a la mónada de buena voluntad. Omnia cooperantur in bonum $^{31}$ (...) Sin duda que a estas preguntas no sabe responder el ser Humano que ha fortalecido y educado su mirada en la intuición del Cosmos, de su armonía y de sus necesidades; pero tampoco se extraña, de que en este caso, como en otros, un infierno venga a ser el corolario natural del Cielo, y aprende, por otra parte, a temerle».

\section{CONCLUSIÓN: OREMOS}

El ensayo de Pierre Teilhard de Chardin «La Vida cósmica» se cierra como en otras ocasiones- con una oración en la que resume y expresa toda la densidad de sentimientos acumulados en su corazón. Reproducimos un fragmento que parece ser más expresivo:

«... Jesús, centro hacia el que todo se mueve, dígnate concedernos a todos, si es posible, un pequeño rincón entre las mónadas escogidas y santas, que una vez desprendidas una a una, por Tu solicitud, del caos actual, se agregan lentamente

30 Referencia a la carta de San Pablo a lo Romanos 8, 22: Scimus enim quod omnis creatura ingemiscit, et parturit usque adhuc. Sabemos que hasta ahora la creación se queja y sufre como una mujer con dolores de parto.

31 Alusión a Romanos 8, 28: «Sabemos que Dios hace converger todas las cosas para bien de aquellos que lo aman, de aquellos que son llamados, según su voluntad salvadora». 
en Ti en la unidad de la nueva Tierra (...) Vivir de la vida cósmica es vivir con la conciencia dominante de que se es un átomo del cuerpo de Cristo místico y cósmico. Quien vive así tiene en nada una multitud de preocupaciones, que para otros resultan absorbentes; vive más distante y su corazón está siempre más abierto».

El ensayo de 1916 «La Vida cósmica» se cierra con tres frases cortas que suministran mucha información sobre el objetivo del escrito, la fecha y el lugar: «Este es mi testamento de intelectual. 24 de abril de 1916. Jueves de Pascua. Fort-Mardik (Dunkerque)» ¿Tal vez pensaba Teilhard que iba a perecer en el frente de batalla? No lo sabemos. El caso es que deseó expresar lo que sentía en esos momentos y poder comunicarlo. En este tiempo, aún no pesaba sobre él ninguna prohibición para publicar sus escritos. Parece que lo que deseaba era comunicárselo a su prima Margarita para que, de alguna manera, sus sentimientos e intuiciones pudieran servir para provecho espiritual.

Bien sabemos que su vida no se segó en el campo de batalla. Todavía tenía por delante su formación como científico en París, los largos años de permanencia en China, las dificultades para poder dar a conocer sus escritos y los duros diez últimos años de su vida, con la sensación íntima de la incomprensión y del desierto exterior e interior. Pero el legado ha podido llegar hasta nosotros.

Doctor en Ciencias Geológicas

LEANDRO SEQUEIROS

Catedrático de Paleontología

Academia de Ciencias Exactas, Físicas y Naturales de Zaragoza.

lsequeiros@probesi.org

http://metanexus.bubok.es

Pintor El Greco 8, 5 4. E-14004 Córdoba

[Artículo aprobado para publicación en diciembre de 2016] 